\title{
5. MAGNETOSTRATIGRAPHY OF CRETACEOUS AGE SEDIMENTS FROM SITES 361, 363, AND 364'
}

\author{
B.H. Keating and C.E. Helsley, The University of Texas at Dallas, Richardson, Texas
}

\begin{abstract}
Investigations of the paleomagnetism of DSDP Sites 361, 363, and 364 enable the recognition of a paleomagnetic reversal sequence for much of the Cretaceous. A long interval of normal polarity is observed in all sites, and corresponds to the previously observed Cretaceous Quiet Zone (Albian through Santonian). Mixed polarity is observed in the Campanian and Maestrichtian samples as well as in Aptian and Albian material. These cores were drilled on the youngest of the $M$ sequence magnetic anomalies, thus the observation of mixed polarity in the Albian and Aptian is unexpected and suggests that several reversals of earth's magnetic field took place in post-MO time.
\end{abstract}

\section{INTRODUCTION}

The magnetostratigraphy of the late Cretaceous has been established through studies of DSDP cores, land sections, and the magnetic anomalies observed in the sea floor (see Keating et al., 1975b); but few paleomagnetic studies of the early Cretaceous have been made. For the pre-Maestrichtian portion of the Cretaceous, we must rely upon the sea-floor anomaly interpretations (summarized by Larson and Hilde, 1975); or upon the older continental work as summarized by Helsley and Steiner (1969). These studies of early and late Cretaceous materials can be combined to provide a basis for predicting polarity within the Cretaceous (Figure 1) although large errors in age assignment and number of polarity zones may remain. Further refinement of this predicted polarity sequence requires the establishment of a detailed magnetostratigraphy for the Cretaceous by means of studies of numerous rock units, some of which must be datable by biostratigraphic means so that the polarity sequence in turn can be correlated with various biostratigraphic zonations, age dates, and marine anomaly patterns.

As a first attempt at establishing a polarity sequence for the early Cretaceous, approximately 1000 oriented samples were collected from three sites drilled in the southern Atlantic during Leg 40 . The objective was to establish the polarity of the core material for use in constructing reversal sequences for the individual cores which could later be correlated with similar results from sites drilled during Legs 41,43 , and 44 . A

'Contribution 310, Geosciences Program, The University of Texas at Dallas, P.O. Box 688, Richardson, Texas. summary of the findings for all four legs is planned for the Leg 44 report.

\section{SAMPLING PROCEDURE}

Samples were collected from DSDP Leg 40, Sites 361,363 and 364 drilled in the southeastern Atlantic Ocean (see Figure 2). For the most part, $2.5-\mathrm{cm}$ diameter cylindrical samples were drilled from the sediment core using a diamond drill bit, and then cut to cylinders $2.5 \mathrm{~cm}$ in length. In the least lithified portions of the core, samples were collected using cylindrical plastic sample holders and in the fissile portions of the core, $1-\mathrm{cm}$ cubes were cut from the core and measured in cubic plastic sample boxes. The procedure followed was to restrict sampling to core segments whose length was greater than the core diameter (this was done to eliminate inversions of core segments which could have taken place in drilling). An arrow marking the up direction was scribed along the center of the split core face. The core segment was then lifted from the core tray and a sample was drilled at right angles to, and centered upon the orientation scribe. A similar procedure was used to cut the $1-\mathrm{cm}$ cubic samples.

The samples were flown to Dallas and refrigerated until measured on a ScT superconducting magnetometer. The samples were refrigerated in order to minimize the chemical, physical, and magnetic changes that take place during desiccation and oxidation. After measurement of the NRM (Natural Remanent Magnetization), a group of samples representing the various lithologic types sampled in the cores was selected for pilot alternating field demagnetization studies using peak fields of 50, 100, 150 , 200, and 300 . Selected portions of the original collection of samples were then demagnetized at an alternating field value deemed appropriate on the basis of the pilot study. 
AGE

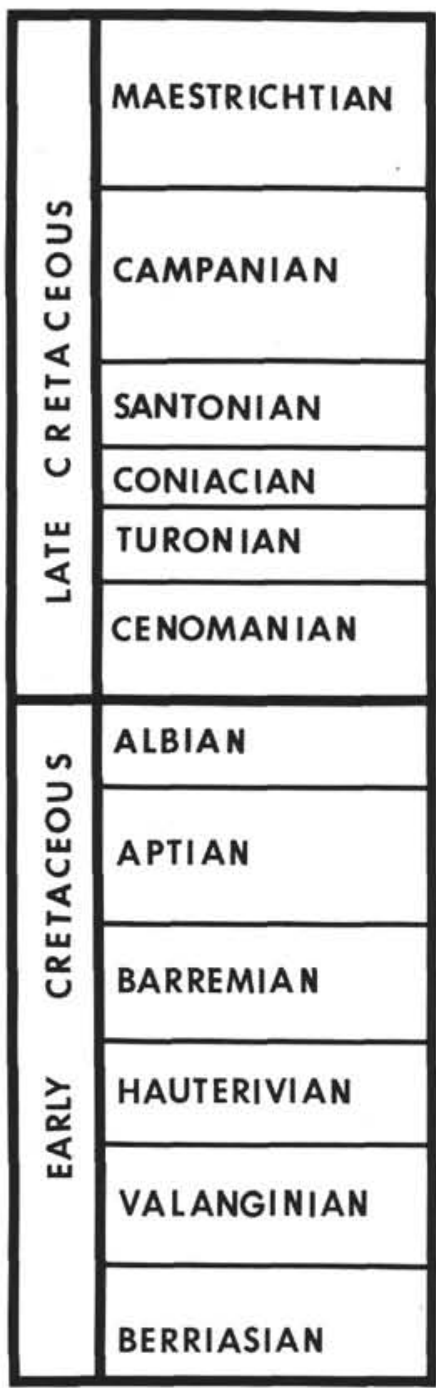

KEATING ET. AL, 1975

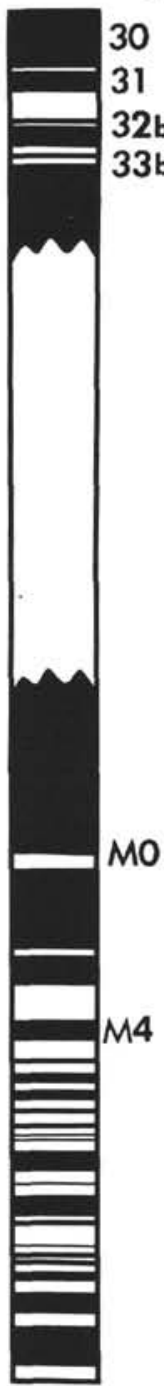

30

31

$32 \mathrm{~b}$

$33 \mathrm{~b}$
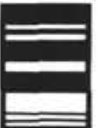

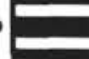

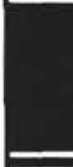

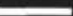

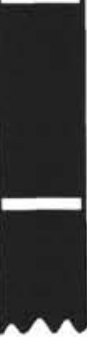

$\sim N$

MO

44

Figure 1. Summary of Cretaceous polarity sequences based upon sea-floor magnetic anomalies and the paleomagnetic study of marine sediment. Summarized from Larson and Hilde, 1975; Sclater and Fisher, 1974; Keating, et al., 1975.

\section{SITE 361}

\section{Stratigraphy}

Site 361 penetrated approximately 1000 meters of Cretaceous sediments. These sediments were divided into two lithologic units by the shipboard scientists. The first (Unit 6) consists of layers of mostly grayish or greenish-black mudstones alternating with reddish mudstone and/or claystone. The environment of deposition was interpreted as abyssal plain to distal fan turbidite facies. The lower portion of the hole (Unit 7) consists of : (1) typically black to dark gray shales; (2) sandy mudstone (greenish-gray to greenish-black; and (3) bluish-gray to greenish-gray sandstone, suggesting an euxinic environment.

Biostratigraphic determinations suggest that Unit 6 (Cores 13-28) ranges in age from Maestrichtian to the Aptian. Unit 7 (Cores 28-48) has been assigned an age of Late Aptian to possibly latest Barremian.

Site 361 was located on the seaward flank of magnetic anomaly M-4. Thus one might expect three intervals of reversed polarity at the bottom of Site 361, barring sedimentary hiatus or gaps due to drilling losses between and within cores.

\section{Sampling}

Approximately 330 samples were collected from Cores 12 through 48, using a sampling interval of approximately $37 \mathrm{~cm}$. Only consolidated samples were collected. Over much of the interval sampled recovery was variable. Recovery overall was about $70 \%$ to $75 \%$. The stratigraphic gaps due to poor core recovery, gaps in the hole between cores, together with the absence of diagnostic microfossils, severely limit the use of Site 361 for the purpose of establishing a magnetostratigraphy for the early Cretaceous.

\section{Stability of Magnetization}

Progressive alternating field demagnetization was carried out on a pilot group of samples consisting of at least one sample of each characteristic lithology sampled (see Table 1). The results of these demagnetization experiments are shown in Figure 3. Large drops in the intensity of magnetization occurred between the initial step and the 100-oe demagnetization step, indicating that a low coercivity (presumably secondary) component of magnetization that makes a significant contribution to the NRM has been removed. Large changes in the inclination (Figure 4) occur between the NRM and 50-oe steps and after the 200and 300-oe steps, while consistent and well-grouped directions appear from 50 to 150 oe. Thus, a 100-oe

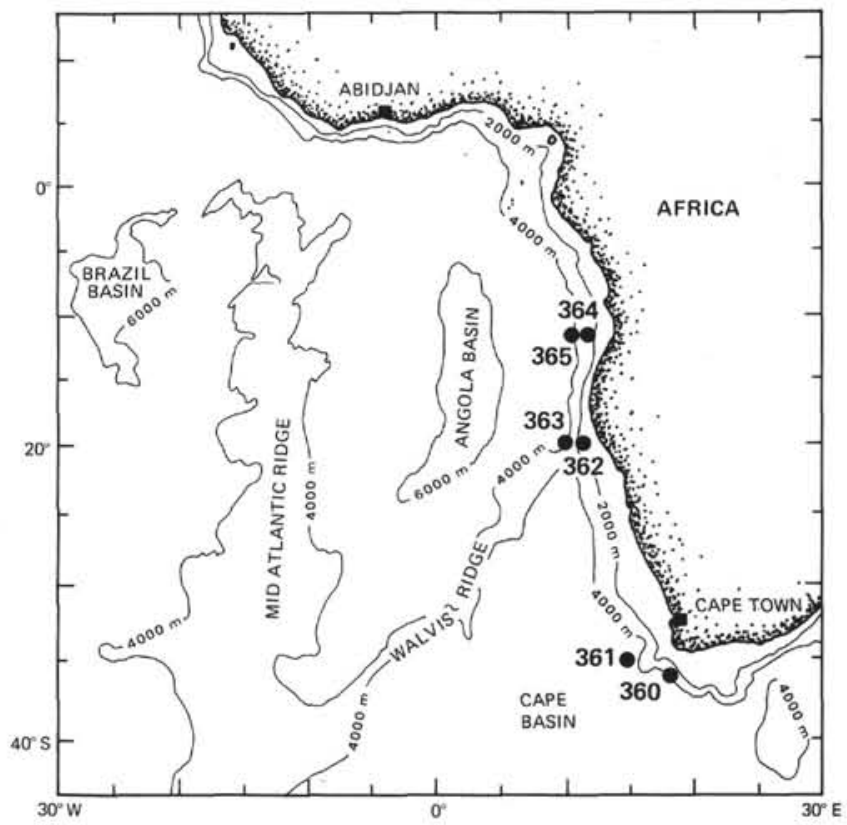

Figure 2. Map of the southeast Atlantic showing positions of drilling sites. 
TABLE 1

\begin{tabular}{ll}
\hline $\begin{array}{c}\text { (Core- } \\
\text { Section- } \\
\text { Interval) }\end{array}$ & \multicolumn{1}{c}{ Lithology } \\
\hline $15-1-129$ & Dark red claystone \\
$18-1-137$ & Brown mudstone \\
$22-1-041$ & Light brown claystone \\
$38-3-111$ & Light gray claystone (turbidite) \\
$43-3-075$ & Dark gray sandstone (turbidite) \\
$43-5-043$ & Light gray coarse-grained \\
& sandstone (turbidite) \\
$45-1-014$ & Bluish-gray sandstone \\
\hline
\end{tabular}

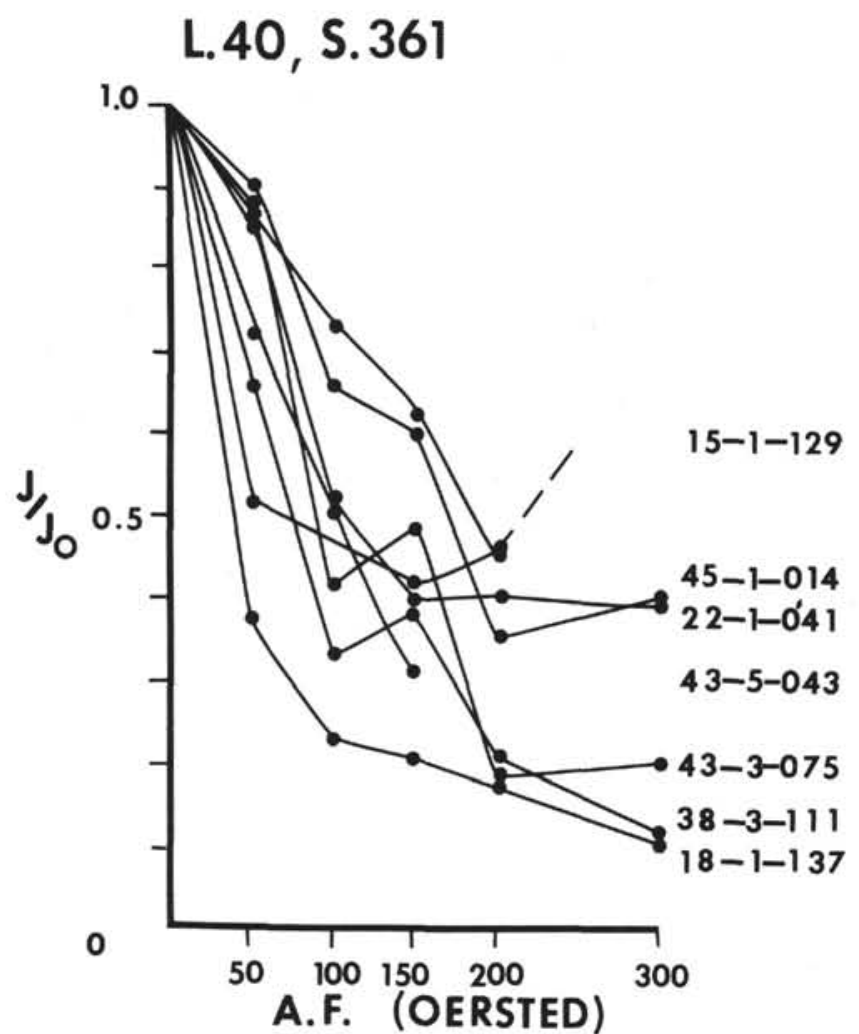

Figure 3. Normalized alternating field demagnetization intensity curves for samples from Site 361. Sample identification indicates level in core from which the sample was taken (core-section, interval). Samples are magnetized in a negative sense (Normal polarity) unless designated as the opposite polarity by $a(+)$ after the identification code.

demagnetization step was used on additional samples since the direction of magnetization seems stable in this range and most of the secondary components of magnetization have been removed.

In order to assess the magnetic polarity sequence, the NRM and alternating field demagnetization results are plotted stratigraphically in Figure 5. Since these cores were drilled in the Southern Hemisphere, it must be remembered that a negative inclination indicates a normal polarity.

Reviewing the NRM results, a pattern of mixed polarity was found in the Maestrichtian (Cores 12-19) and upper Aptian (Cores 27-47) portions of the core.

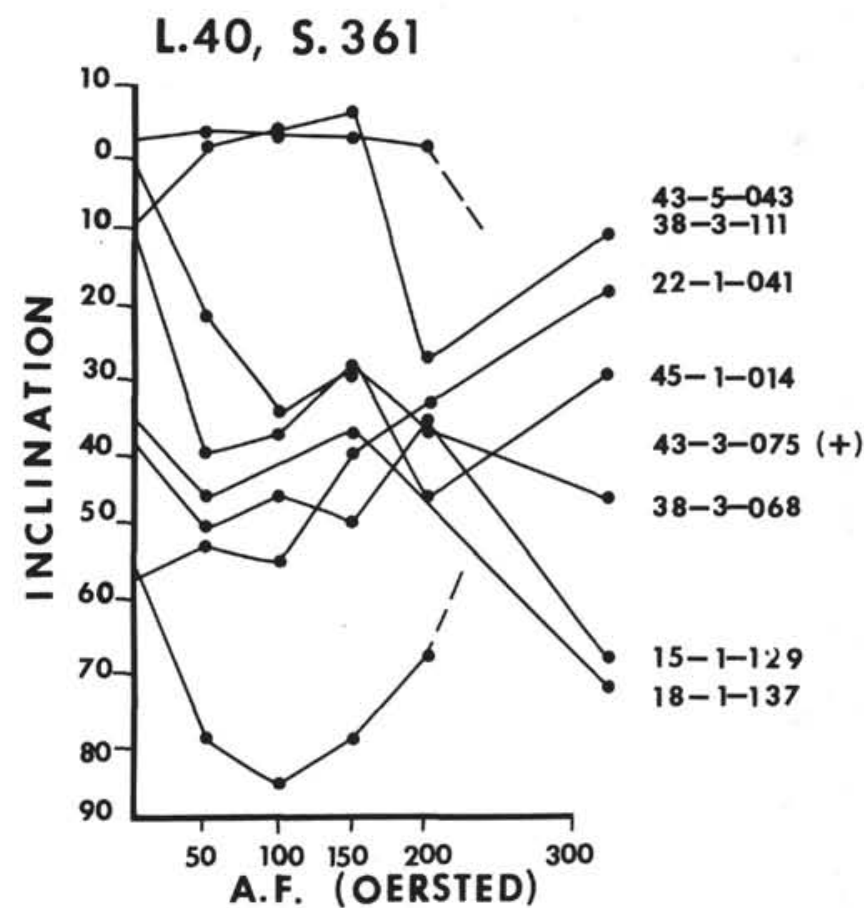

Figure 4. Change in inclination with demagnetization. Sample identifier indicates position in core (coresection-depth). All samples are magnetized in a negative sense, indicating normal magnetization (southern hemisphere) unless otherwise noted. Dashed lines indicate change in direction with corresponding decrease in intensity down to $1 \%$ of original intensity (interpreted as an unreliable direction).

The intervals of mixed polarity are separated by an interval of constant normal polarity. Previous magnetostratigraphic studies of the Cretaceous (Keating, et al., 1975a, 1975b; Helsley and Steiner, 1969) have identified a similar pattern of frequent reversals, followed by a period of constant polarity which in turn is succeeded by frequent reversals. This constant polarity interval has since been named the Cretaceous Quiet Interval.

As explained previously, the magnetostratigraphy of the Maestrichtian has been studied in detail (Keating et al., 1974, 1975). However, no detailed study has been completed on early Cretaceous sediments. Thus, an attempt was made through further demagnetization of the Aptian portion of the core to clarify the reversal sequence in the early Cretaceous. The results of the alternating field demagnetization are plotted in Figure 5 , along with the NRM data.

\section{Results}

Two intervals of reversed polarity were found in the Maestrichtian portion of the core. The latter of the two reversals (Core 14-2) corresponds to reversed polarity recorded in the Rugotruncana subcircumnodifer Subzone of the Pessagno Zonation and probably corresponds to sea-floor Anomaly 33b. Four additional intervals of reversed polarity were found in Cores 43 to 47 . These cores have been assigned an age of early Aptian. The four reversed polarity zones found at the 

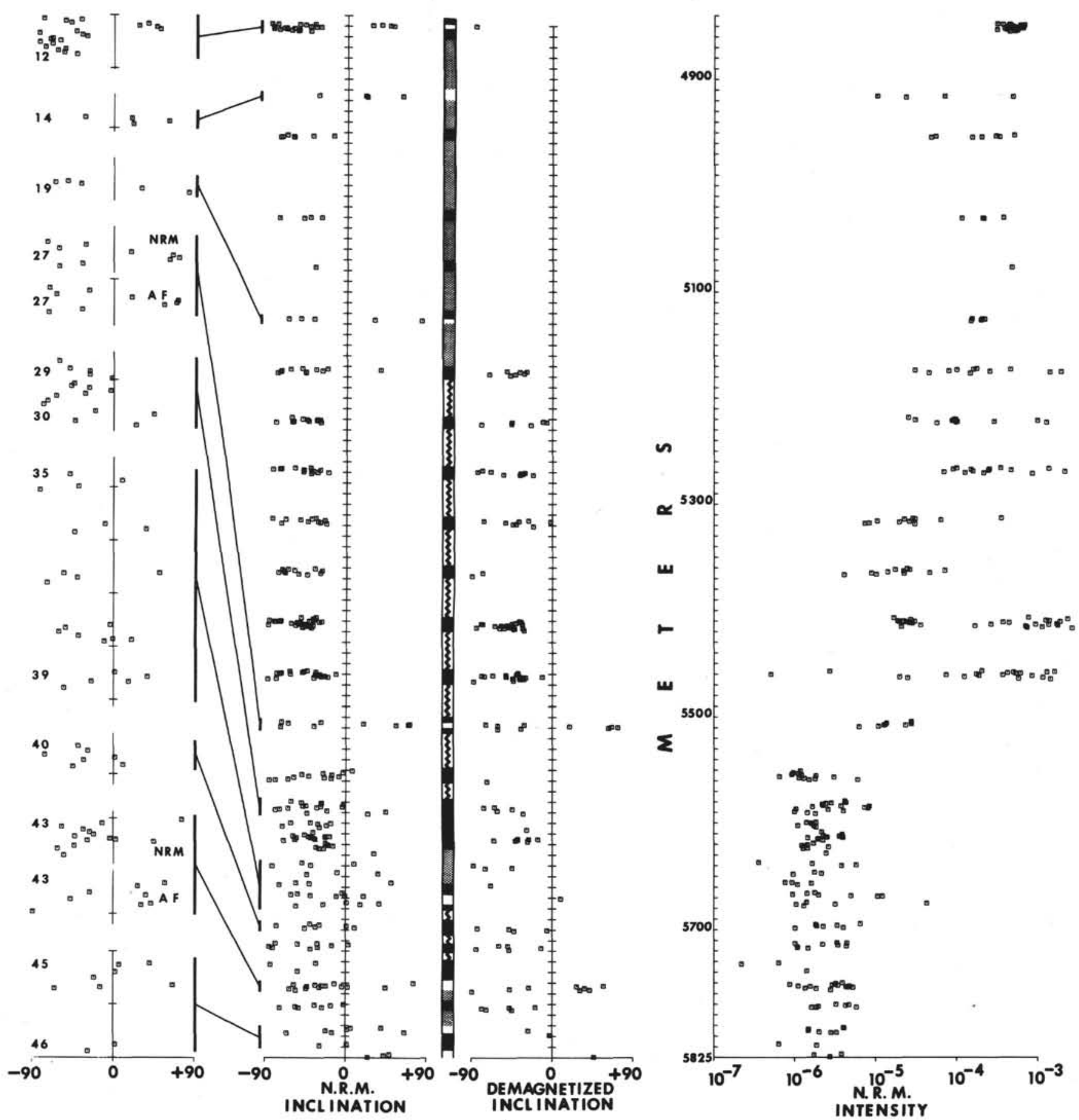

Figure 5. Stratigraphic plot of sample inclinations and intensity for Hole 361. Sample intensity is measured in emu uncorrected for variable sample volume. NRM and demagnetized inclinations are shown in separate columns. The intensity plotted is the NRM intensity per sample uncorrected for variations in sample volume. Intervals with mixed polarity are shown in expanded sections (vertical scale expanded 5 times that of NRM inclination column) to the left of the diagram. Each tick mark represents 10 meters. Gaps between data points are due to poor recovery or gaps between adjacent cores. Black represents normal polarity; white represents reversed polarity, zig-zag indicates the polarity is unknown but probably normal, the stipple pattern indicates the polarity is unknown. The gaps between clusters of data points indicate gaps between cores. Depths on vertical scale are referenced to drill rig floor. 
bottom of this hole may correspond to reversals within the $\mathrm{M}$-sequence. An additional reversed polarity zone of early Aptian age was found in Core 27 and another was found in Core 19 which lies well above the predicted M-sequence (Larson and Hilde, 1975) and may postdate the M-sequence.

\section{SITE 363}

\section{Stratigraphy}

A total of 40 cores as collected at Site 363 and, of these, approximately half (Cores 18-39) were sampled for magnetostratigraphic studies. Three stratigraphic units were sampled; the first (Unit 1) being foraminiferal and nanno fossil oozes and chalks (including Cores 18-21). These cores show evidence of current activity including fine laminations richer in terrigenous material than surrounding chalks; occasionally showing grading or cross-bedding. Partial recrystallization may have occurred in these cores. A very low sedimentation rate is given for this lithologic unit. Unit 2 consists of marly chalks, limestones, calcareous mudstones, and limestones (Cores 22-29). The chalk and mudstones were cyclically bedded and range from brown to greenish-gray. Cores 26 to 29 show numerous erosional contacts and has several thin layers with abundant pyrite. Unit 3 consists of light brownish-gray foraminiferal limestone with a few calcarenite layers.

Biostratigraphic studies suggest that the portion of Unit 1 sampled was Maestrichtian in age, ranging from the Globotruncana linneiana Zone to the Abathomphalus mayaroensis Zone (early to late Maestrichtian). Unit 2 ranges from Maestrichtian-Campanian to Late AptianAlbian in age. An abrupt change in microfossils occurs between Cores 25 and 26, indicative of a hiatus. This hiatus is believed to occur between sediments of Coniacian-Santonian age and Albian age. Cores 26 through 40 are assigned a Turonian to Aptian age.

The initial sedimentation at Site 363 is believed to be coincident with or slightly younger than the basement isochrone $\mathrm{M}-\mathrm{O}$ as inferred from the sites' position seaward of the continental edge and on strike with the projection of magnetic anomaly M-O. Thus, based on the established reversal sequence, one should expect to find mixed polarity in the upper few cores, followed by an interval of constant (normal) polarity. According to the paleomagnetic studies of land-based sedimentary sequences (Helsley and Steiner, 1969), reversed polarity should occur again in the Albian or Aptian. However, if the location of the site in regard to the sea-floor magnetic anomaly is correct, no reversals should be found in the lower portion of the core.

\section{Paleomagnetic Measurements}

Two hundred and forty-two samples were collected from Cores 18 through 39 at this site. Recovery at this site averaged $59.7 \%$, with about $33 \%$ of the sediment column sampled. A summary of the various lithologies selected for the pilot group demagnetization studies at steps from 50 to 300 oe (peak alternating field) is given in Table 2. As with the previous site, large drops in intensity occurred between the initial step and the 100 -
TABLE 2

\begin{tabular}{ll}
\hline $\begin{array}{c}\text { (Core- } \\
\text { Section- } \\
\text { Interval) }\end{array}$ & \multicolumn{1}{c}{ Lithology } \\
\hline $18-1-093$ & Pale brown nannofossil chalk \\
$19-5-071$ & Pink nannofossil chalk \\
$23-1-085$ & Grayish-brown nannofossil chalk \\
$28-3-137$ & White marly limestone \\
$34-3-014$ & Light gray limestone \\
$36-2-002$ & Gray limestone \\
$39-2-002$ & Yellowish-gray limestone
\end{tabular}

oe demagnetization step (Figure 6), indicating a significant secondary component of magnetization has been removed. A large change in the inclination (see Figure 7) occurs between the initial measurement and the 50-oe step, while fairly consistent directions occur at all other demagnetization steps, with the exception of two samples. In both these cases, the intensity has dropped to less than $1 \%$ of its original value and, thus, the recorded directions are probably unreliable. On the basis of the pilot study, a 100-oe demagnetization step was chosen as appropriate and samples from the early Cretaceous portion of the core were demagnetized in this field. Only consolidated sediments which were drilled as cylindrical cores were demagnetized. The NRM intensity and inclinations and the demagnetized inclinations are plotted stratigraphically in Figure 8.

\section{Results}

As was predicted by comparison with the established reversal sequence (Figure 1), mixed polarity was found in the Maestrichtian portion of the core. An additional reversal was found in Core 33, Section 2. Since it is restricted to one core segment, this suggests that the segment may have been inadvertantly inverted. If this is not the case, then the single reversal may postdate the $\mathrm{M}$-sequence and correlate with post-M sequence magnetic anomalies mentioned by Larson and Hilde, 1975. Alternatively, if the positioning relative to $\mathrm{M}-\mathrm{O}$ is incorrect, the reversal may correspond to the first of the M-sequence anomalies.

\section{SITE 364}

\section{Stratigraphy}

A total of 31 cores of the 45 cores collected at Site 364 was sampled for paleomagnetic study. The sediments sampled were divided into four lithologic units by shipboard scientists. The first, Unit 4 (Cores 7-19), consists of a calcareous nannofossil chalk and marly chalk. Unit 5 (Cores 20-25) consists of a marly chalk with finely laminated sapropels. Unit 6 (Cores 26-38) consists of marly chalk and limestone containing some steeply dipping bedding contacts and styolites. Unit 7 (Cores 39-46) consist of finely laminated sapropelitic limestone and shale which become bituminous and dolomitic toward the bottom of the hole. The depositional environment is considered to be euxinic.

Biostratigraphic determinations suggest that Unit 4 ranges from late Campanian to Santonian in age. Unit 


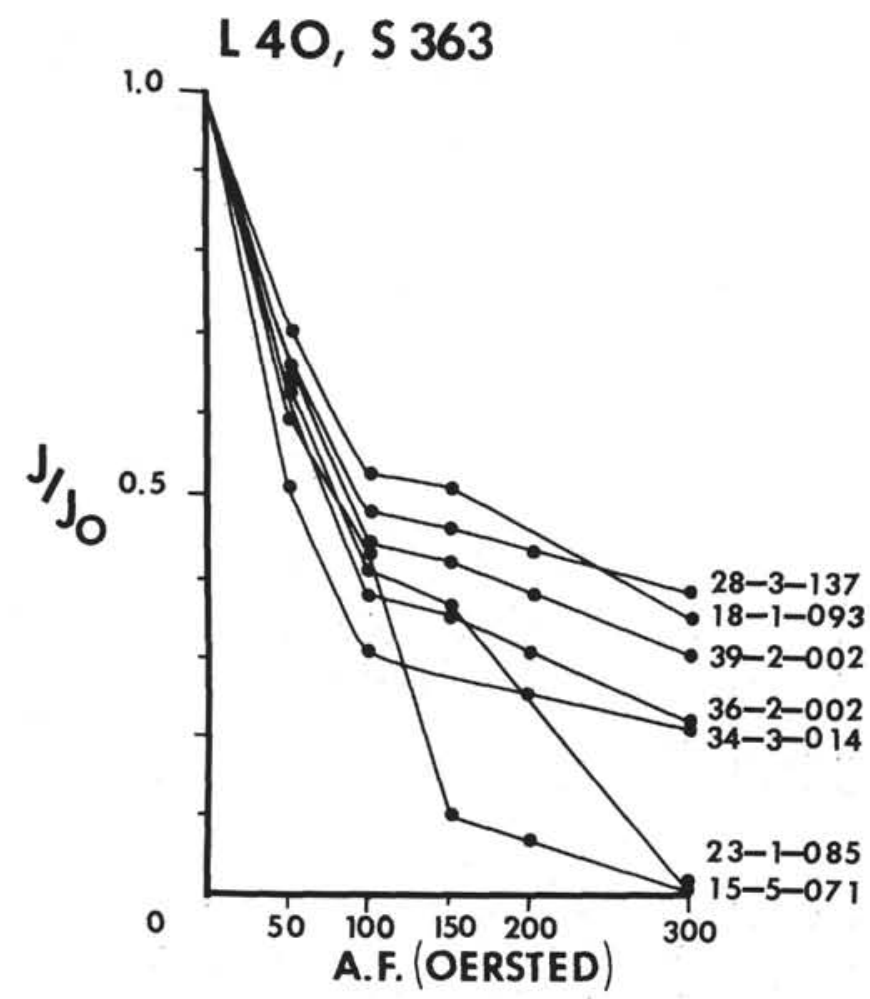

Figure 6. Normalized alternating field demagnetization curves for samples from Site 363. Sample identification indicates level in core from which the sample was taken.

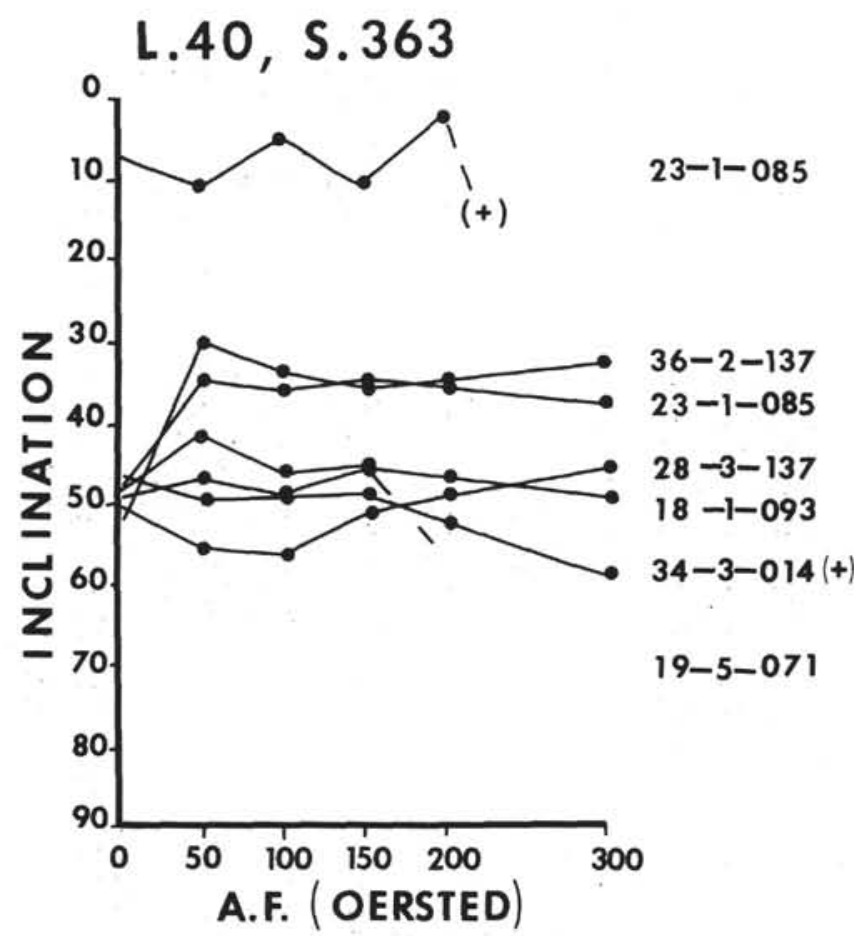

Figure 7. Change in inclination with demagnetization. Sample identifier indicates position in core /coresection-depth). Dashed lines indicate change in direction with corresponding decrease in intensity to $1 \%$ of original intensity (interpreted as unreliable direction).
5 is assigned an age of Coniacian to Cenomanian and the upper portion of Unit 6 is assigned an age of Cenomanian to middle Albian. An early Albian age assignment is made for cores from Core 41 downward to the bottom of the hole.

Site 364 was drilled on magnetic anomaly M-4 and although acoustic basement was not reached, one might expect to encounter the late Cretaceous zone of normal polarity and perhaps some of the M-sequence reversed polarity intervals near the base of the hole.

\section{Paleomagnetic Measurements}

Four hundred and thirty-two samples were collected from Cores 14 through 45 at this site. Stratigraphic plots of inclination and intensity are shown in Figure 9. Unlike Sites 361 and 363, none of the samples from this site were demagnetized since manuscript deadlines left insufficient time for additional measurements. Thus, the polarity is based solely on NRM results. However, it should be noted that demagnetized results from the two previous sites have confirmed the initial polarity assignments made on the basis of NRM measurements.

Mixed polarity was found to be present in the Paleocene portion of this core. This finding agrees with mixed polarity reported from the study of sea-floor magnetic anomalies reported by Heirtzler et al., 1968. Mixed polarity was also found in that portion of the core assigned an early Maestrichtian-late Campanian age (perhaps corresponding to the double reversal labeled $33 \mathrm{~b}$ in the sea-floor anomaly sequence.). An additional long reversed interval encountered in Cores 16 and 17 probably corresponds to sea-floor anomaly 34. Mixed polarity (five reversed zones) also occurs in that portion of the core assigned a Cenomanian to early Albian age, again indicating that more reversed zones are present in this portion of the stratigraphic column than can be accommodated by current magnetic anomaly models.

\section{SUMMARY}

Over 1,000 samples were collected from DSDP Sites 361,363 and 364 in an attempt to construct a paleomagnetic reversal sequence for a portion of the early Cretaceous. The attempt was in the large part unsuccessful due to poor core recovery, large gaps between cores, and lack of precise paleontological control.

A number of illuminating observations, however, can be made despite the desultory sampling. First, and perhaps most important, is the presence of long intervals of normal polarity within Cores 361,363 , and 364 , which corresponds to the Cretaceous Quiet Interval. Second, mixed polarity is found in the upper Cretaceous (Maestrichtian) and Paleocene, as is observed elsewhere. Third, at least one (perhaps more) interval of reversed polarity occurs within the Aptian. This reversed polarity interval is present in all cores and is previously unreported in studies of sea-floor magnetic anomaly patterns, or in the study of continental rocks. The fourth observation is very intriguing. Two sites, 361 and 364 , are located on 
L. $40,5.363$
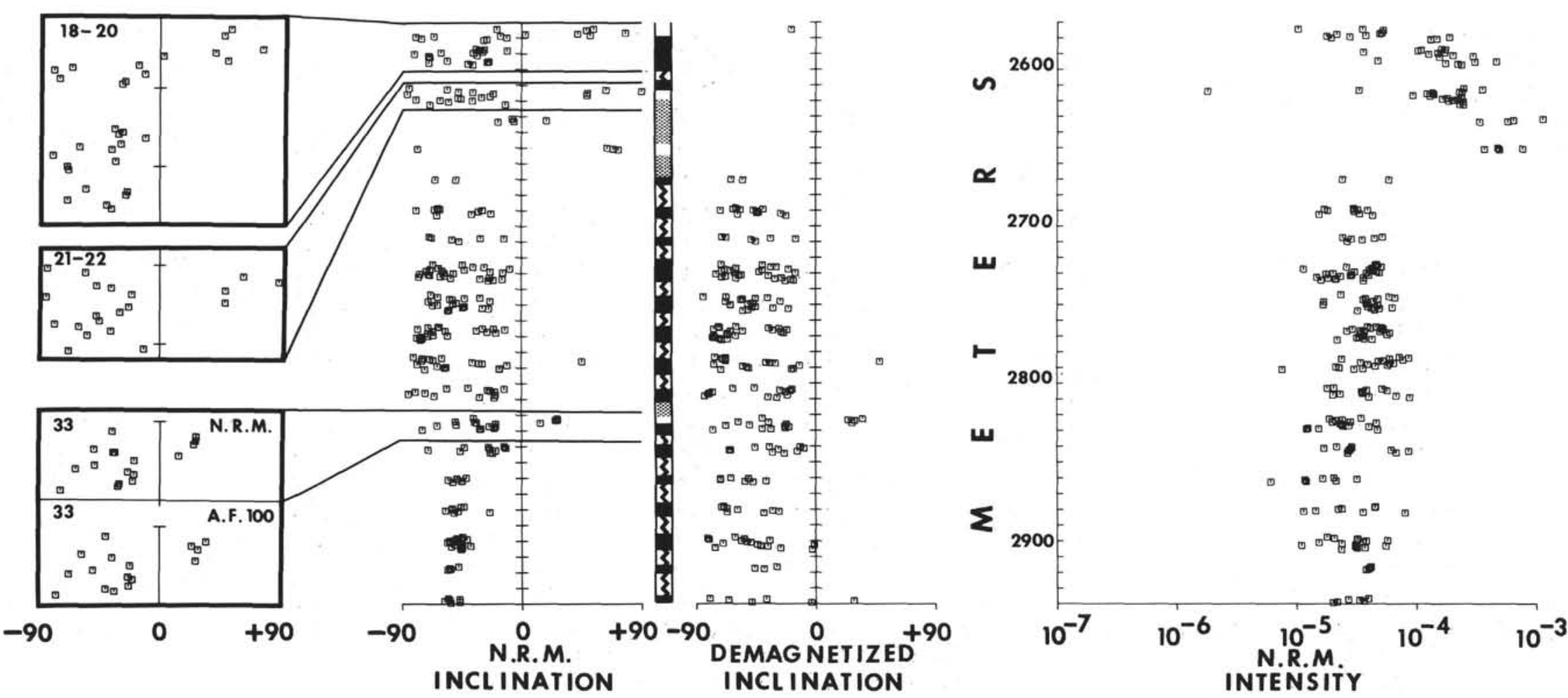

Figure 8. Stratigraphic plot of sample inclinations and intensity for Site 363. Sample intensity is measured in emu/sample uncorrected for variations in sample volumes. Intervals with both normal and reversed polarity are shown with a $5 \mathrm{X}$ expansion of the vertical scale to the left. Inclinations after demagnetization are shown between the stratigraphic plots of NRM inclination and NRM intensity. (Negative inclinations indicate normal polarity within the southern hemisphere). 

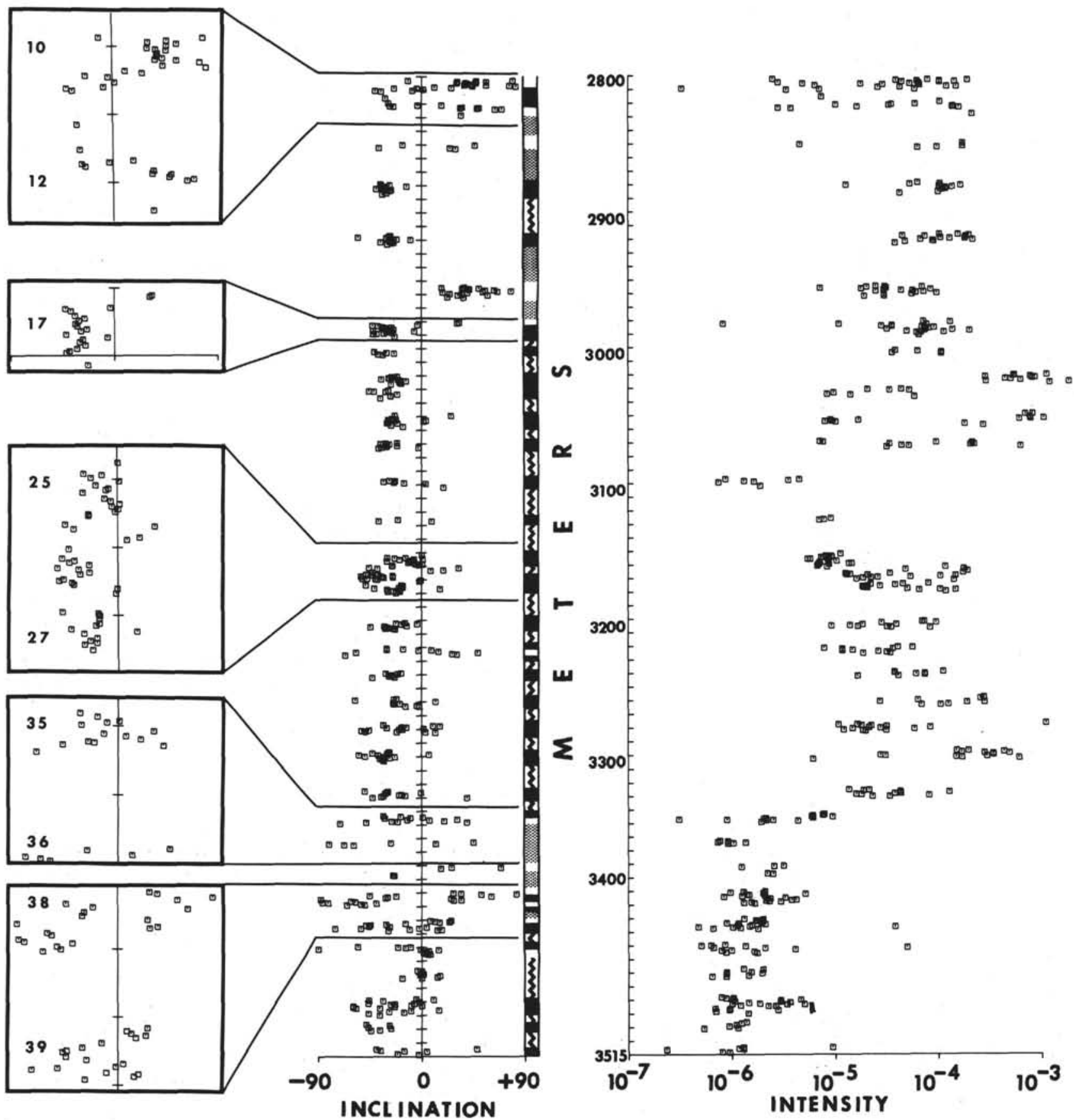

Figure 9. Stratigraphic plot of sample inclinations and intensity. Intervals in which both normal and reversed polarity are found are shown with a $5 \mathrm{X}$ expansion of the vertical scale to the left of the NRM inclination column.

anomaly M-4, based upon the study of marine magnetic anomalies in the region. Thus three reversed intervals should be found in the lower part of each of these cores. The last of these reversed intervals should be fairly long. The interesting point is that despite gaps in coring and recovery and in the case of Site 364 the presence of 3000 meters of salt between the bottom of the hole and the acoustic basement, more reversals were found than are predicted by Larson and Hilde's reversal sequence. One likely explanation for this occurrence is that these cores have recorded post-M- sequence anomalies, the existence of which has been suggested by Hilde, 1975.

Finally, a correlation has been noted between the occurrence of weakly magnetized intervals with the presence of $1 \%$ or more pyrite. This coincidence of low intensity and presence of pyrite is notable in Cores 28 to 47 of Site 361 and Cores 23 to 24, and 35 to 45 of Site 364.

These sites from Leg 40 will not add greatly to the construction of a continuous composite polarity sequence, but they do substantiate previous work and 
suggest the presence of additional reversals which have not yet been reported from the study of sea-floor magnetic anomaly patterns.

\section{ACKNOWLEDGMENTS}

We would like to thank John Fiske for his help during the three weeks required to collect these samples at Lamont, especially for his willingness to put snow tires on the core carts. In addition, we owe thanks to Barry Lienert for aid with programs and equipment; and Jane Neugent who keypunched data from this and other legs. This work was supported by the National Science Foundation under Grant GA43299.

\section{REFERENCES}

Heirtzler, J.R., Dickson, G.O., Herron, E.M., Pitman, W.C. III, and LePichon, X., 1968. Marine magnetic anomalies, geomagnetic field reversals and motions of the ocean floor and continents: J. Geophys. Res., 73, p. 2119.

Helsley, C.E. and Steiner, M.B., 1969. Evidence for long intervals of normal polarity during the Cretaceous period: Earth Planet. Sci. Let., v. 5, p. 325.
Helsley, C.E., 1973. Post paleozoic magnetic reversals: Abstracts With Program, G.S.A. Annual Meeting, v. 5, p. 665 .

Hilde, T.W.C., 1973. Mesozoic sea-floor spreading in the North Pacific: D. Sc. Thesis, Univ. of Tokyo, Tokyo, Japan.

Keating, B.H., Helsley, C.E., and Pessagno, E.A., Jr., 1974. Late Cretaceous reversals: EOS, Trans. Am. Geophys. Union, v. 55, p. 236.

Keating, B.H., Helsley, C.E., Pessagno, E.A., Jr., 1975a. Late Cretaceous reversal sequence: Geology, v. 2, p. 73.

Keating, B.H., Helsley, C. E., Pessagno, E.A. Jr., 1975b. Reversed events within the Late Cretaceous normal polarity interval: EOS, Trans. Am. Geophys. Union, v. 56, p. 354.

Larson, R.L., and Hilde, T.W.C., 1975. A revised time scale of magnetic reversals for the Early Cretaceous and Late Jurrassic: J. Geophys. Res., v. 80, p. 2586.

Sclater, J.G. and Fisher, R.L., 1974. Evolution of the east central Indian Ocean with emphasis on the tectonic setting of the Ninetyeast Ridge: Geol. Soc. Am. Bull., v. 85, p. 683 . 